\title{
Test for Measuring the Stretchability of Melted Cheese ${ }^{1}$
}

\author{
R. L. Fife ${ }^{\star 2}$ D. J. McMahon, ${ }^{*}$ and C. J. Oberg† \\ *Western Dairy Center, \\ Department of Nutrition and Food Sciences, \\ Utah State University, Logan 84322 \\ †Department of Microbiology, \\ Weber State University, \\ Ogden UT 84408
}

\begin{abstract}
A test for measuring the stretchability of cheese was developed by adapting a texture-profile analyzer to pull strands of cheese upwards from a reservoir of melted cheese. Seven different cheeses were analyzed using the Utah State University stretch test. The cheeses were also analyzed for apparent viscosity with a helical viscometer, for meltability using a tube melt test, and for stretch using the pizza-fork test. Cheese was placed into a stainless steel cup and tempered in a water bath at $60,70,80$, or $90^{\circ} \mathrm{C}$ for $30 \mathrm{~min}$ before analysis. The cup was then placed in a water-jacketed holder mounted on the base of the instrument. A three-pronged hook-shaped probe was lowered into the melted cheese and then pulled vertically until all cheese strands broke or $30 \mathrm{~cm}$ was reached. This produced a stretch profile as the probe was lifted through the reservoir of melted cheese and then pulled strands of cheese upwards. Three parameters were defined to characterize the stretchability of the cheese. The maximum load, obtained as the probe was lifted through the cheese, was defined as melt strength $\left(\mathrm{F}_{\mathrm{M}}\right)$. The distance to which cheese strands were lifted was defined as stretch length (SL). The load exerted on the probe as the strands of cheese were being stretched was defined as stretch quality (SQ). There was a correlation between $\mathrm{F}_{\mathrm{M}}$ and apparent viscosity. There was also some correlation between SL measured by the fork test and SL when the cheese was tested at $90^{\circ} \mathrm{C}$, but no correlation occurred at lower temperatures.
\end{abstract}

(Key words: mozzarella, pizza, fork test, functionality)

Abbreviation key: LMPS = low-moisture part-skim, $\mathbf{N F}=$ nonfat, $\mathbf{F}_{\mathbf{M}}=$ melt strength, $\mathbf{S Q}_{\mathbf{5}}=$ stretch quality

Received April 1, 2002.

Accepted May 15, 2002

Corresponding author: D. J. McMahon; e-mail: djm@cc.usu.edu.

${ }^{1}$ Contribution Number 7428 of the Utah Agricultural Experiment Station. Approved by the director.

${ }^{2}$ Current address: Schrieber Foods, P.O. Box 19010, Green Bay, WI 54307. at 5-cm extension, $\mathbf{S Q}_{\mathbf{2 0}}=$ stretch quality at 20 -cm extension, $\mathbf{S L}=$ stretch length, USU = Utah State University .

\section{INTRODUCTION}

One of the most important characteristics of Mozzarella cheese used as pizza topping, but the most difficult to measure is the ability of the cheese to stretch when melted. Stretch refers to the capacity of melted cheese to form fibrous strands that extend under tension (Kindstedt, 1995). The method most commonly used by cheese manufacturers and pizza companies is the fork test, in which cheese is baked on a pizza and then tested for how far it will stretch (U. S. Department of Agriculture, 1980). In this test, grated cheese is placed on a pizza crust containing pizza sauce, and after the pizza is baked, a fork is inserted into the melted cheese and raised vertically until all the cheese strands break. Strand length at the time the strands break is used as a measure of stretchability of the cheese. Although some test parameters are controlled (e.g., time and temperature of baking) most technicians perform the fork test differently. Where and how the fork is inserted, tine orientation, the amount of tine covered by the cheese, and the speed used to lift the cheese can all vary. In addition, defining the point at which the majority of the strands break depends on the experience and judgment of the technician performing the test. It has been said that with the fork test one can obtain any desired result simply by varying how the test is performed. Because the fork test is so subjective, it is not uncommon for evaluations of the same cheese to differ.

A number of methods have been proposed to evaluate the stretch properties of cheese. Helical viscometry was suggested as a way to measure stretchability of cheese (Kindstedt et al., 1989a, 1989b; Oberg et al., 1991). However, our experience with helical viscometry melt profiles indicates it primarily gives a measure of apparent viscosity of melted cheese plus some qualitative information on stretch characteristics that could be obtained from the area of the melt profile after the T-bar rises above the cheese surface. Measurements by helical viscometry 
FIFE ET AL.

Table 1. Composition of cheeses used for evaluating the stretch test.

\begin{tabular}{llllll}
\hline Cheese & Fat & Moisture & Protein & Salt $^{1}$ & Ca \\
\hline & & & & & \\
\cline { 2 - 5 } NF-1 & $<0.1$ & 58.9 & 28.7 & 1.6 & 0.86 \\
NF-2 & $<0.1$ & 56.3 & 26.9 & 1.8 & 0.78 \\
NF-3 & $<0.1$ & 60.3 & 31.9 & 1.4 & 0.52 \\
LMPS-1 & 20.0 & 45.6 & 25.3 & 1.2 & 0.76 \\
LMPS-2 & 20.5 & 49.9 & 23.0 & 1.5 & 0.72 \\
LMPS-3 & 19.5 & 47.3 & 24.5 & 0.9 & 0.59 \\
LMPS-4 & 20.5 & 48.1 & 23.2 & 1.3 & 0.62 \\
\hline
\end{tabular}

${ }^{1}$ Salt calculated as $\mathrm{Na}$ content $\times 2.54$.

had been shown (Oberg et al., 1991) to be inversely related to the melt test of Olson and Price (1958). However, measurements of viscosity and extent of cheese melting are not the same as measuring stretch.

Various types of tensile tests of melted cheese have been developed as possible replacements for the fork test (Cavella et al., 1992; Ak et al., 1993; Ak and Gunasekaran, 1995). Apostolopoulos (1994) proposed a test based on how consumers would assess the stretchability of cheese on a pizza. A circular plate was used as a template to hold a pizza crust, and a smaller circular piece (with a vertical rod attached) was cut out, allowing the center of the template to be raised independently of the edge. A similarly cut pizza crust was placed on the template and a standard weight of cheese sprinkled on top of the crust. The complete apparatus was heated in a microwave oven for $15 \mathrm{~s}$ to melt the cheese. On removal from the oven, the vertical rod was attached to the head of a tensile testing machine and pulled vertically, stretching the melted cheese. The extensibility of the cheese was taken as the distance of travel until all the cheese strands broke. This method was modified by Guinee and O'Callaghan (1997), such that the two halves of a cheesecovered pizza were pulled horizontally, rather than vertically. Stretch was also defined as the distance the cheese stretched until complete strand failure.

The purpose of this research was to develop a simple and objective test for measuring the stretchability of melted Mozzarella cheese that would allow cheese makers and pizza makers to predict how cheese would perform as a pizza topping. The measurements from the stretch test were then compared to other common tests used to evaluate mozzarella cheese performance.

\section{MATERIALS AND METHODS}

\section{Cheese}

Seven cheese samples were used to evaluate the stretch test (see Table 1 for cheese composition). They consisted of three nonfat (NF) cheeses and four lowmoisture part-skim (LMPS) Mozzarella cheeses. Fat was measured in duplicate using a modified Babcock method (Marshall, 1992). Cheese moisture was measured in triplicate by vacuum-oven AOAC method 926.08, and protein was measured in duplicate by AOAC method 920.105 (AOAC, 1990). Mineral content was measured using inductively coupled plasma-atomic spectroscopy (U. S. Environmental Protection Agency, 1992).

\section{Stretch Test}

A tensile tester (Model 25; Stevens Farnell, Dunmorow, United Kingdom) was modified to evaluate the stretch properties of cheese. Stainless steel sample cups for holding the melted cheese, and a water-jacketed sample cup holder were fabricated. The cup holder was mounted to the base of the instrument and attached to a circulating water bath (Techne Inc., Princeton, NJ). The water bath was used to temper the cheese samples prior to testing and to maintain sample temperature during the stretch test.

Cheese plugs (height: $3.5 \mathrm{~cm}$; diameter: $3.0 \mathrm{~cm}$ ) were placed into the cups (height: $5.0 \mathrm{~cm}$; diameter: $3.4 \mathrm{~cm}$ ), covered with aluminum foil to prevent evaporation, then tempered in the water bath for $30 \mathrm{~min}$ at $60,70,80$ or $90^{\circ} \mathrm{C}$ (Figure 1). A sample cup containing the molten cheese was then placed in the water-jacketed sample cup holder (Figure 2). A three-prong spindle (see Figure 2 and Figure 3) was lowered into the melted cheese until it was $0.3 \mathrm{~cm}$ from the bottom of the cup. The sample cup was rotated 1/6 turn (to provide an uncut area of the cheese) and locked into position. After $30 \mathrm{~s}$, the cheese was pulled vertically (Figure 4) at $100 \mathrm{~cm} / \mathrm{min}$ for $30 \mathrm{~cm}$, the output of load-versus-time was converted to load-versus-distance and the data smoothed using a running average of five data points. Typically, the weight of cheese attached to the probe at the completion of the test was approximately $5 \mathrm{~g}$, so breaking of the strands was defined as the point at which the load fell below $5 \mathrm{~g}$.

\section{Other Tests}

Melt was measured using a modified (oil bath, $95^{\circ} \mathrm{C}$ ) tube test method (McMahon et al., 1999). The distance 


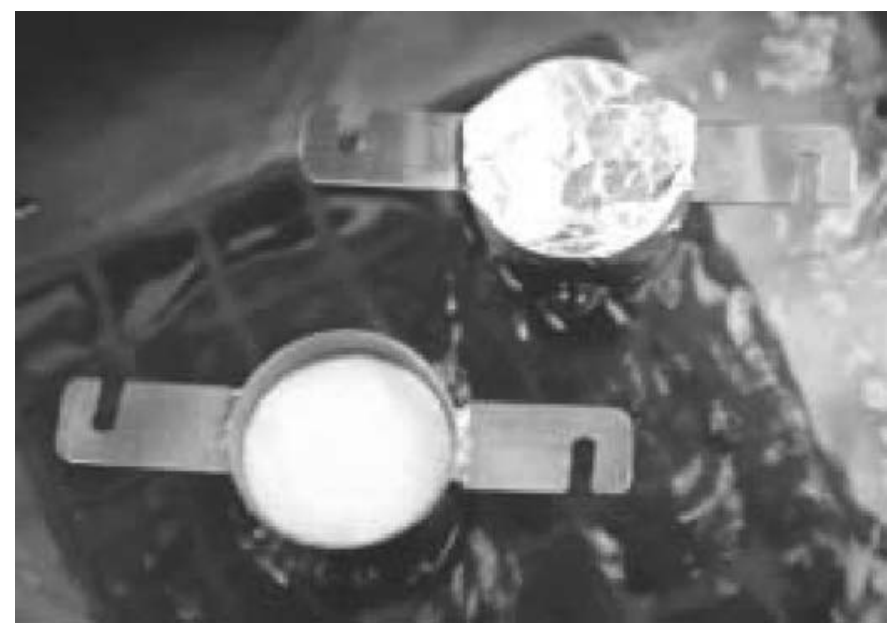

Figure 1. Cheese being tempered in the water bath prior to analysis.

the cheese had flowed by 12 min was used to compare cheese meltability. Apparent viscosity was measured using the method of Kindstedt et al. (1989a), with modifications by Fife et al. (1996), in which apparent viscosity was measured while the T-bar was fully immersed in the melted cheese. Cheese was also tested using a fork test, in which $114 \mathrm{~g}$ of pizza sauce (Kraft Food Service, Inc., Glenview, IL) was evenly distributed on a thawed 30-cm diameter pizza crust (Krusteaz; Continental Mills, Seattle, WA) followed by $284 \mathrm{~g}$ of shredded cheese. The pizza was then baked at $250^{\circ} \mathrm{C}$ for 6 min in a conveyer-style oven (Impinger, Model 1302; Lincoln Food Service Products, Inc., Fort Wayne, IN). Baked pizzas were allowed to cool at room temperature (approximately

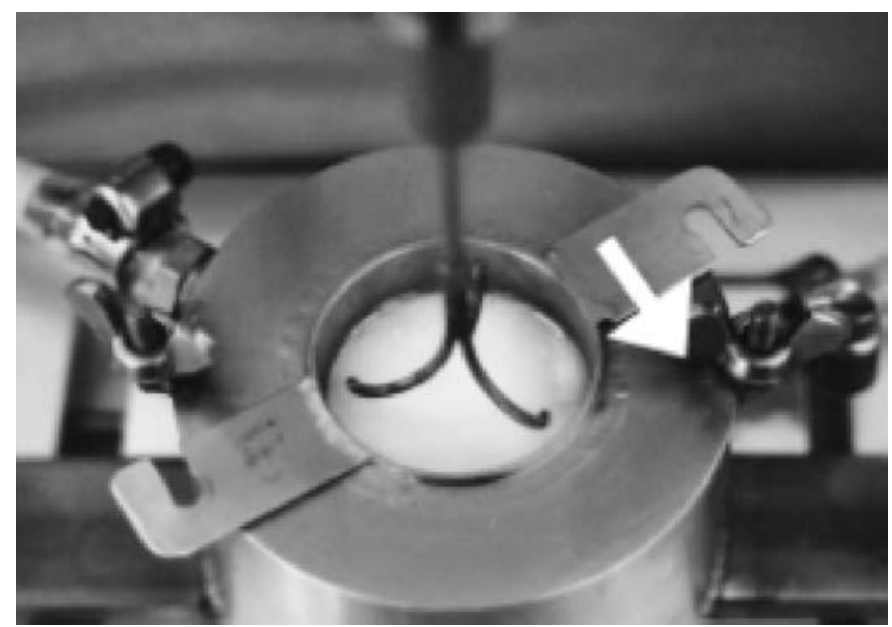

Figure 2. Sample in position prior to conducting the stretch test. After lowering the probe into the cheese, the sample cup was rotated clockwise $45^{\circ}$. $22^{\circ} \mathrm{C}$ ) for $1.5 \mathrm{~min}$. A fork was inserted into the melted cheese, then lifted vertically until the cheese strands broke. The distance the cheese strands could be extended was recorded.

\section{RESULTS AND DISCUSSION}

\section{Stretch Profile}

The force-time dataset produced by this test was termed the "stretch profile," and it could be divided into two regions based on the relative position of the probe to the melted cheese pool (Figure 5). The initial part of the stretch profile, region 1 , covered the portion of the stretch profile from crosshead actuation until the probe lifted from the melted cheese. As the probe is pulled through the melted cheese, a resistant load is exacted on the probe. This load increases rapidly from the time of crosshead actuation until the probe travels through approximately one-half of the melted cheese and then decreases as the probe passes through and egresses the upper half of the melted cheese.

Region 2 covered the portion of the stretch profile after the probe lifted above the melted cheese. As the probe

Front View

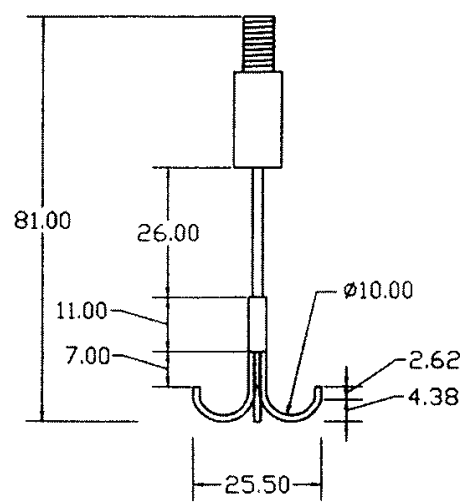

Top View

(Scaled up $2 \mathrm{X}$ )

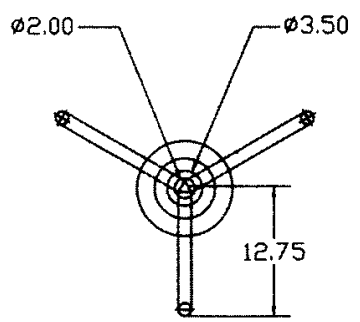

Figure 3. Dimensions $(\mathrm{mm})$ of tri-probe used for the USU Stretch Test. 


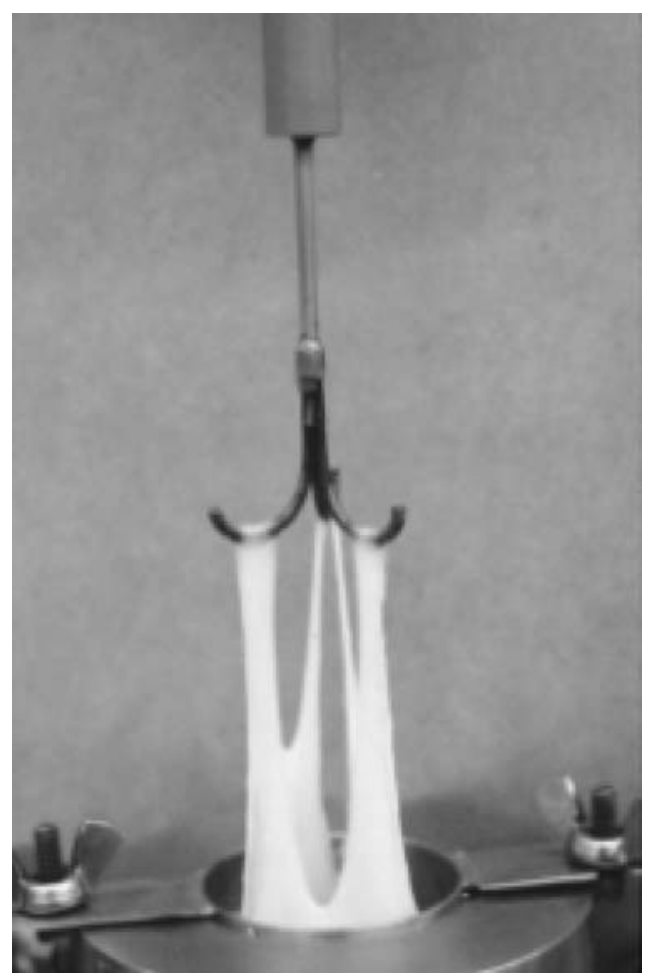

Figure 4. Strands of cheese being pulled upward during the USU Stretch Test.

leaves the cheese surface, a portion of the cheese remains attached to the probe depending on the stretch characteristics of the cheese. Additional cheese is pulled from the reservoir of melted cheese, and the cheese is further stretched as the probe continues to lift. During this time, the load on the load cell decreases, and a relatively constant load is obtained until the cheese strands break. Within region 2 , cheese strands may extend to the maximum distance (i.e., $30 \mathrm{~cm}$ ), break before reaching $30 \mathrm{~cm}$ of extension, or thin to hair-like strands that reach 30 $\mathrm{cm}$ of extension (although in this case the weight of such strands is below the 5-g level set as the minimum). From the stretch profile, three parameters were chosen to characterize the cheese-stretching properties of the cheese (Figure 6).

Melt strength $\left(\mathbf{F}_{\mathbf{M}}\right)$ was defined as the maximum load (g) obtained during the tensile test. This occurs as the probe is pulled through the molten cheese in region 1 of the stretch profile and can be considered a function of viscosity and elasticity of the melted cheese. Stretch quality (SQ) was defined as the load (g) exerted during the time that strands of cheese are being pulled upwards from the melted cheese reservoir. Load measurements at 5 and $20 \mathrm{~cm}$ of extensibility were designated as $\mathbf{S Q}_{\mathbf{5}}$ and $\mathbf{S Q}_{\mathbf{2 0}}$, respectively. Stretch length (SL) was defined
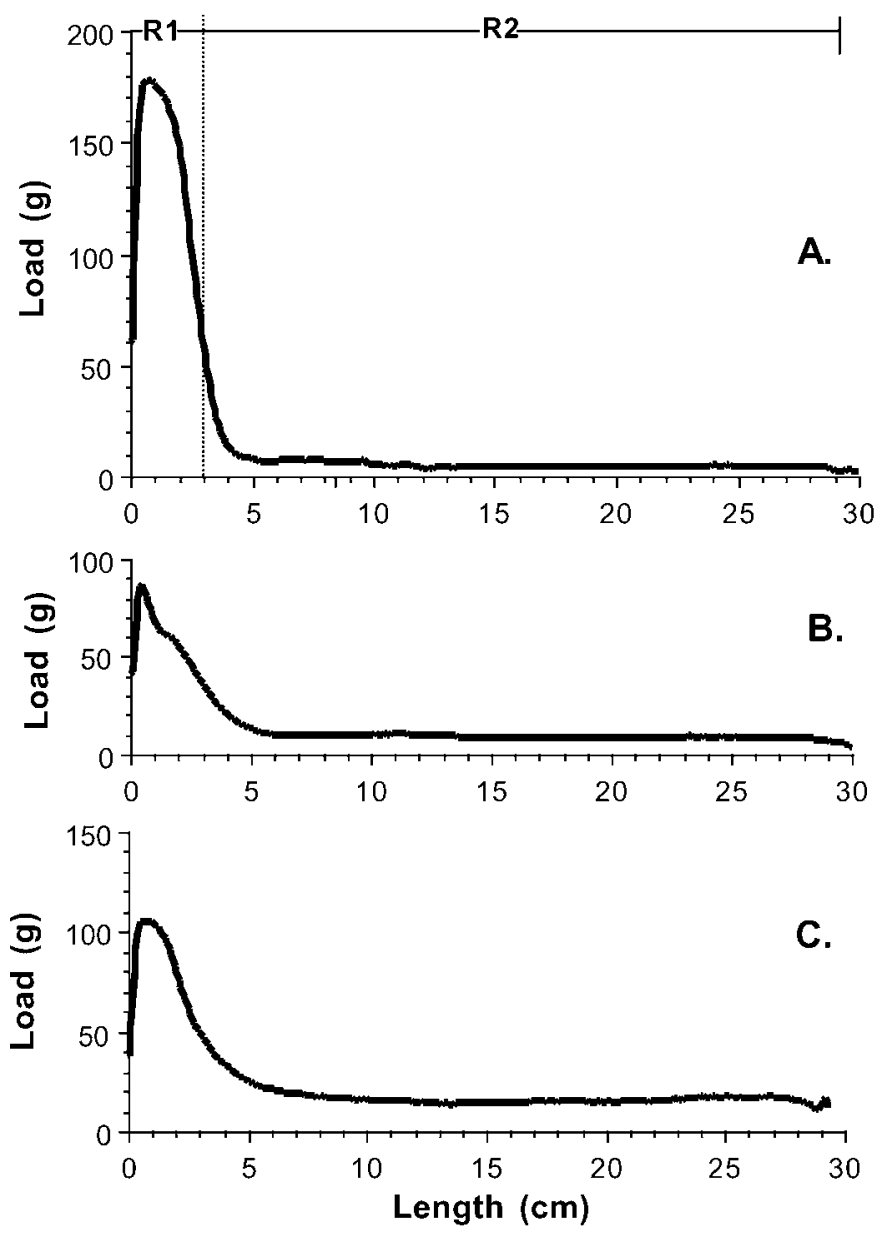

Figure 5. Examples of the stretch profiles of three cheeses at $70^{\circ} \mathrm{C}$. Region 1 (R1) represent the distance from cross-head actuation until the probe exits the melted cheese pool; region 2 (R2) represents the distance the probe travels from the melted cheese pool surface until the probe stops at $30 \mathrm{~cm}$. Figure $5 \mathrm{a}$ is a nonfat cheese (NF-2); whereas Figures 5b and 5c are low-moisture part-skim Mozzarella cheeses (LMPS-1 and LMPS-4, respectively).

as the distance the cheese strands remained attached to the spindle and exerted a load $\geq 5 \mathrm{~g}$.

In addition to the tri-probe (Figures 2 and 3), we also tested a T-bar probe (similar in shape to that used for helical viscometry) and an X-bar probe. However, both of these failed to lift adequate amounts of cheese. Peña et al. (1996) evaluated different types of probes for measuring the stretchability of melted cheese, including a tined fork, a solid beam, and a rectangular wire frame. They obtained the better correlation between textural rankings and sensory results when using the rectangular wire frame configuration. The curved tri-probe that we used in the Utah State University (USU) Stretch Test worked well for lifting strands of cheese from the melted cheese reservoir.

When individual cheeses were tested at different temperatures $\left(60,70,80\right.$, and $\left.90^{\circ} \mathrm{C}\right)$, different stretch profiles 
Table 2. Mean $( \pm \mathrm{SEM})$ of melt strength $\left(\mathrm{F}_{\mathrm{M}}\right)$, stretch quality at $5 \mathrm{~cm}\left(\mathrm{SQ}_{5}\right)$ and stretch quality at $20 \mathrm{~cm}$ $\left(\mathrm{SQ}_{20}\right)$ of extension, and stretch length (SL) of nonfat (NF) and low moisture part-skim (LMPS) Mozzarella cheese tested at $60,70,80$ and $90^{\circ} \mathrm{C}(\mathrm{n}=2)$.

\begin{tabular}{|c|c|c|c|c|}
\hline \multirow[b]{2}{*}{ Cheese } & \multicolumn{4}{|c|}{ Stretch parameters } \\
\hline & $\mathrm{F}_{\mathrm{M}}$ & $\mathrm{SQ}_{5}$ & $\mathrm{SQ}_{20}$ & SL \\
\hline & 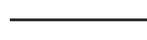 & - (g) & - & $(\mathrm{cm})$ \\
\hline \multicolumn{5}{|l|}{$60^{\circ} \mathrm{C}$} \\
\hline NF-1 & $243 \pm 29$ & $116 \pm 9$ & $45 \pm 0$ & $30 \pm 0$ \\
\hline NF-2 & $182 \pm 42$ & $13 \pm 6$ & $6 \pm 1$ & $17 \pm 11$ \\
\hline $\mathrm{NF}-3$ & $136 \pm 11$ & $44 \pm 5$ & $12 \pm 0$ & $30 \pm 0$ \\
\hline LMPS-1 & $254 \pm 25$ & $53 \pm 3$ & $16 \pm 3$ & $30 \pm 0$ \\
\hline LMPS-2 & $117 \pm 1$ & $9 \pm 1$ & $6 \pm 1$ & $18 \pm 12$ \\
\hline LMPS-3 & $218 \pm 13$ & $55 \pm 0$ & $21 \pm 2$ & $30 \pm 0$ \\
\hline LMPS-4 & $259 \pm 15$ & $110 \pm 13$ & $29 \pm 2$ & $30 \pm 0$ \\
\hline \multicolumn{5}{|l|}{$70^{\circ} \mathrm{C}$} \\
\hline NF-1 & $145 \pm 7$ & $32 \pm 3$ & $13 \pm 1$ & $30 \pm 0$ \\
\hline NF-2 & $178 \pm 20$ & $7 \pm 1$ & $4 \pm 0$ & $9 \pm 1$ \\
\hline NF-3 & $92 \pm 3$ & $18 \pm 0$ & $8 \pm 0$ & $30 \pm 0$ \\
\hline LMPS-1 & $87 \pm 19$ & $12 \pm 4$ & $8 \pm 2$ & $29 \pm 1$ \\
\hline LMPS-2 & $84 \pm 13$ & $28 \pm 12$ & $12 \pm 7$ & $21 \pm 9$ \\
\hline LMPS-3 & $98 \pm 2$ & $14 \pm 2$ & $13 \pm 1$ & $30 \pm 0$ \\
\hline LMPS-4 & $105 \pm 4$ & $25 \pm 2$ & $15 \pm 1$ & $29 \pm 0$ \\
\hline \multicolumn{5}{|l|}{$80^{\circ} \mathrm{C}$} \\
\hline NF-1 & $92 \pm 2$ & $48 \pm 6$ & $14 \pm 1$ & $30 \pm 0$ \\
\hline NF-2 & $279 \pm 23$ & $11 \pm 7$ & $11 \pm 6$ & $17 \pm 13$ \\
\hline NF-3 & $53 \pm 1$ & $11 \pm 0$ & $5 \pm 0$ & $7 \pm 1$ \\
\hline LMPS-1 & $50 \pm 8$ & $9 \pm 1$ & $6 \pm 1$ & $17 \pm 11$ \\
\hline LMPS-2 & $40 \pm 4$ & $5 \pm 0$ & $1 \pm 0$ & $5 \pm 0$ \\
\hline LMPS-3 & $68 \pm 4$ & $13 \pm 1$ & $6 \pm 1$ & $17 \pm 6$ \\
\hline LMPS-4 & $53 \pm 2$ & $14 \pm 2$ & $10 \pm 1$ & $30 \pm 0$ \\
\hline \multicolumn{5}{|l|}{$90^{\circ} \mathrm{C}$} \\
\hline NF-1 & $93 \pm 4$ & $34 \pm 7$ & $22 \pm 8$ & $29 \pm 1$ \\
\hline NF-2 & $263 \pm 1$ & $5 \pm 1$ & $6 \pm 3$ & $17 \pm 12$ \\
\hline NF-3 & $51 \pm 6$ & $15 \pm 3$ & $5 \pm 1$ & $8 \pm 2$ \\
\hline LMPS-1 & $47 \pm 13$ & $3 \pm 0$ & $3 \pm 1$ & $4 \pm 1$ \\
\hline LMPS-2 & $41 \pm 2$ & $6 \pm 0$ & $3 \pm 1$ & $5 \pm 1$ \\
\hline LMPS-3 & $73 \pm 5$ & $17 \pm 9$ & $3 \pm 0$ & $5 \pm 1$ \\
\hline LMPS-4 & $54 \pm 2$ & $18 \pm 3$ & $15 \pm 0$ & $30 \pm 0$ \\
\hline
\end{tabular}

were obtained at each temperature (see Figure 6 and Table 2). In general, $\mathrm{F}_{\mathrm{M}}$ decreased as the testing temperature increased. The exception was NF-2 which contained inulin, and because inulin forms a gel at $80^{\circ} \mathrm{C}$, both $\mathrm{F}_{\mathrm{M}}$ (Table 2) and apparent viscosity (Figure 7) of NF-2 increased with temperature. SQ also decreased for most cheeses when temperature was increased.

\section{Melt Strength}

While the probe remained in the melted cheese pool, the resistant force exerted on the probe was caused by many of the same force components as those exerted on the T-bar spindle used to determine apparent viscosity. Those forces included the upward pull of the spindle, cheese viscosity, cheese fiber formation around the spindle, and the capacity of the cheese fibers to resist deformation. However, the rotational forces associated with helical viscometry were absent in the USU stretch test. This similarity between the force components was reflected in a relatively high correlation between $\mathrm{F}_{\mathrm{M}}$ and apparent viscosity $\left(R^{2}=0.77\right)$. Typically, the maximum load $\left(\mathrm{F}_{\mathrm{M}}\right)$ exerted on the probe occurred when the probe had been pulled through approximately half the melted cheese pool. Load values dropped off quickly as the probe was pulled through the upper half of the melted cheese pool with full egression from the cheese surface at approximately $3 \mathrm{~s}$.

In Figure 5, the variation in stretch profiles between different types of cheese stretched at the same temperature $\left(70^{\circ} \mathrm{C}\right)$ can be observed. For example, the $\mathrm{F}_{\mathrm{M}}$ of cheese NF-2 (Figure 5a) was twice that of cheese LMPS1 (Figure 5b) while, cheese LMPS-4 (Figure 5c) had an intermediate $F_{M}$ value. It had previously been reported that apparent viscosity of cheese was inversely related to meltability of cheese (Oberg et al., 1991, 1992), but this did not occur when cheeses of very different composition (fat, protein and calcium) and age were compared. Only a low correlation between meltability and apparent viscosity $\left(R^{2}=0.11\right)$ or meltability and $F_{M}\left(R^{2}=0.18\right)$ was observed. The cheeses had a wide range of meltabil- 

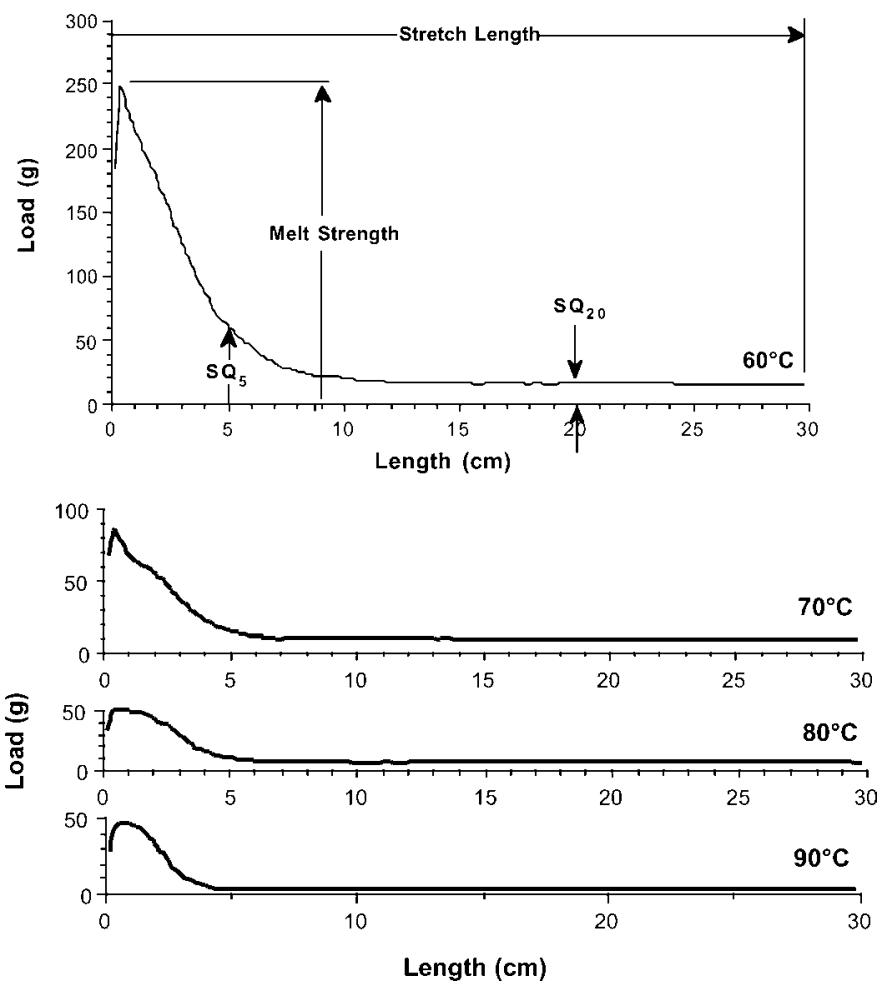

Figure 6. Stretch profiles of a low- moisture part-skim Mozzarella cheese (LMPS-1) analyzed at $60,70,80$, and $90^{\circ} \mathrm{C}$, showing the three parameters used to characterize stretch: melt strength (maximum load as the probe is lifted through the melted cheese), stretch length (distance cheese can be extended before load $\leq 5 \mathrm{~g}$ ), and stretch quality (load at 5 and $20 \mathrm{~cm}$ of extension and designated as $\mathrm{SQ}_{5}$ and $\mathrm{SQ}_{20}$, respectively).

ity, with 12-min melt distances ranging from 6 to $17 \mathrm{~cm}$ (Table 3).

\section{Stretch Quality}

SQ measures the ability of cheese strands to stretch until the point at which they break in response to being pulled upward by the probe. Measurement of SQ in terms of resistance to the upward pull of the probe provides additional information over that provided in other proposed stretch tests methods (Apostolopoulos, 1994; Guinee et al., 1997), which use only a length measurement to characterize stretch. SQ provides a numerical measure of what is subjectively observed during the fork test. When the fork test was used to evaluate the cheeses, it was observed that the NF cheeses stretched to a greater degree than did LMPS cheeses, but the NF cheeses tended to form very thin strands, whereas the LMPS cheeses formed thicker strands. When comparing cheeses, the SQ values should be considered in conjunction with $\mathrm{F}_{\mathrm{M}}$. For example, when tested at $70^{\circ} \mathrm{C}$, cheese NF-2 had higher $\mathrm{F}_{\mathrm{M}}$ values than LMPS-4, but LMPS-4

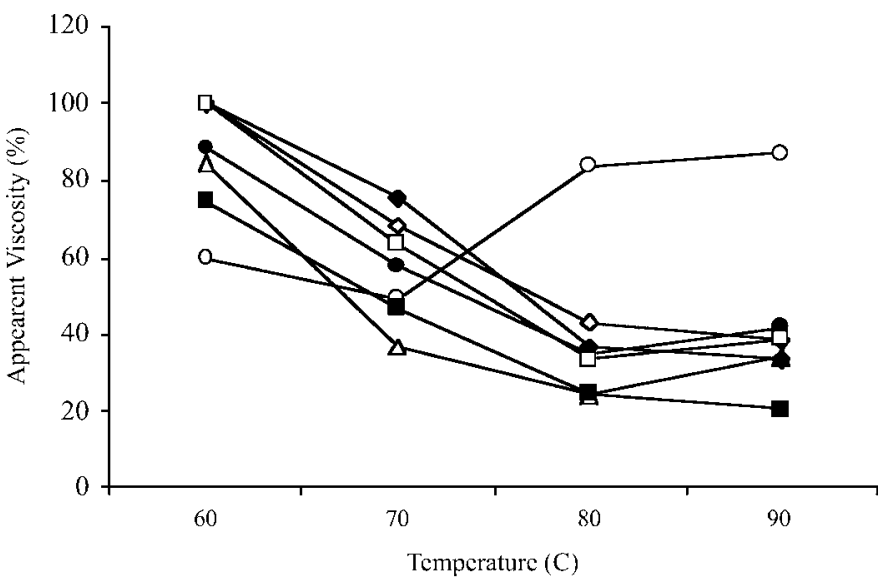

Figure 7. Relative apparent viscosity of nonfat (NF) and lowmoisture part-skim (LMPS) Mozzarella cheeses at 60, 70, 80, and $90^{\circ} \mathrm{C}$ : NF-1 (open diamond), NF-2 (open circle), NF-3, (open triangle), LMPS-1 (solid diamond), LMPS-2 (solid square), LMPS-3 (solid circle), and LMPS-4 (open square).

had higher SQ values. The temperature at which the cheese is tested also influences the results (see Figure 6 and Table 3) because the apparent viscosity of most cheeses decrease as temperature is increased (Figure 7). Performing the test at two temperatures, for example, 70 and $90^{\circ} \mathrm{C}$, may help provide information on how cheese will act when served on a pizza to the consumer, as well as during the baking process.

Selection of $\mathrm{SQ}_{5}$ and $\mathrm{SQ}_{20}$ for measurement of $\mathrm{SQ}$ was because in preliminary studies, all cheeses stretched to a minimum $5 \mathrm{~cm}$ of extension, and most cheeses stretched more than $20 \mathrm{~cm}$. Measurement of $\mathrm{SQ}_{5}$ provides an indication of initial strand formation and is somewhat dependent on the magnitude of $\mathrm{F}_{\mathrm{M}}\left(\mathrm{R}^{2}=0.33\right)$, whereas $\mathrm{SQ}_{20}$ relies more on continued pulling of cheese from the reservoir of molten cheese There was, however, a correlation between $\mathrm{SQ}_{5}$ and $\mathrm{SQ}_{20}\left(\mathrm{R}^{2}=0.80\right)$ with $\mathrm{SQ}_{20}$ being less than $\mathrm{SQ}_{5}$.

\section{Stretch Length}

In the past, maximum cheese extensibility has been the primary method for evaluating cheese stretchability. However, no methodology has been standardized, and there is no agreed interpretation of stretch data. Our experience with helical viscometry, the fork test, and with the USU Stretch Test, demonstrates that maximum extensibility should not be the sole determinant of cheese stretchability. In helical viscometry, it is not uncommon for a single hair-sized strand of cheese to extend the entire travel-distance of the helipath (approximately 22 $\mathrm{cm}$ ). We have also observed extremely thin strands of cheese extending from the melted cheese pool to the 
Table 3. Mean $( \pm$ SEM) melt distance and fork test stretch distance of nonfat (NF) and low moisture part-skim (LMPS) Mozzarella cheeses $(n=2)$.

\begin{tabular}{lrr}
\hline Cheese & \multicolumn{1}{l}{$\begin{array}{l}\text { Melt } \\
\text { distance }\end{array}$} & $\begin{array}{l}\text { Fork test } \\
\text { distance }\end{array}$ \\
\cline { 2 - 3 } NF-1 & $9.0 \pm 0.3$ & \\
NF-2 & $6.8 \pm 0.0$ & $28.8 \pm 1.8$ \\
NF-3 & $9.6 \pm 0.2$ & $23.8 \pm 1.8$ \\
LMPS-1 & $16.9 \pm 1.1$ & $32.5 \pm 0.0$ \\
LMPS-2 & $10.8 \pm 2.4$ & $8.8 \pm 1.8$ \\
LMPS-3 & $6.0 \pm 0.0$ & $12.5 \pm 0.0$ \\
LMPS-4 & $9.1 \pm 0.1$ & $5.0 \pm 0.0$ \\
\end{tabular}

probe during the USU Stretch Test. Although these strands extended from the probe to the cheese pool, none were large enough to be detected by the load cell. At $60^{\circ} \mathrm{C}$, most of the cheeses stretched to the maximum extension of $30 \mathrm{~cm}$, but as temperature increased, there was a tendency for SL to decrease (Table 2). When compared to the distance the cheese could be lifted using the fork test (Table 3), there was no correlation between the fork test and SL when the cheese was tested at 60 or $70^{\circ} \mathrm{C}\left(\mathrm{R}^{2}<0.1\right)$. There was some correlation at $90^{\circ} \mathrm{C}$ $\left(\mathrm{R}^{2}=0.52\right)$ which suggests that in the $1.5 \mathrm{~min}$ the pizza is allowed to cool before conducting the fork test, the bulk of the cheese on the pizza had not cooled very much. The inherent variations that occur in the fork test make it very difficult for the fork test to be correlated with any other test. Using a test (such as the USU Stretch Test) that can be conducted under standardized and reproducible conditions would allow for better communication between cheese manufacturers and their customers about the stretching performance of cheese.

\section{CONCLUSIONS}

Differences in melted cheese performance were objectively measured by the USU Stretch Test, using a combination of descriptive parameters based on the load exerted on a three-pronged hook-shaped probe as the cheese was stretched. $\mathrm{F}_{\mathrm{M}}$ (the maximum load exerted on the probe as the cheese was stretched) was correlated with apparent viscosity and provides an indication of how well the cheese would melt during baking on a pizza. How well the cheese stretches can be described in terms of distance (SL) and resistive load (SQ). Testing the cheese at different temperatures (e.g., $90^{\circ} \mathrm{C}$ and $70^{\circ} \mathrm{C}$ ) may provide information on predicted performance of the cheese during baking, as well as at the time it is consumed. We propose that this stretch test could be used by cheese manufacturers as a means of obtaining more quantitative information on cheese performance that could be more readily reproduced between laboratories than the fork test that is currently being used.

\section{ACKNOWLEDGMENT}

We thank Khalid Shammet for suggestions on probe design.

\section{REFERENCES}

Ak, M. M., D. Bogenrief, S. Gunasekaran, and N. F. Olson. 1993. Rheological evaluation of Mozzarella cheese by uniaxial horizontal extension. J. Texture Studies 24:437-453.

Ak, M. M., and S. Gunasekaran. 1995. Measuring elongational properties of Mozzarella cheese. J. Textural Studies. 26:147-160.

Apostolopoulos, C. 1994. Simple empirical and fundamental methods to determine objectively the stretchability of Mozzarella cheese. J. Dairy Res. 61:405-413.

Association of Official Analytical Chemists (AOAC). 1990. Official Methods of Analysis. Vol. 2. 15th ed. AOAC, Arlington, VA.

Cavella, S., S. Chemin, and P. Masi. 1992. Objective measurement of the stretchability of Mozzarella cheese. J. Texture Studies. 23:185-194.

Fife, R. L., D. J. McMahon, and C. J. Oberg. 1996. Functionality of low fat Mozzarella cheese. J. Dairy Sci. 79:1903-1910.

Guinee, T. P., and D. J. O'Callaghan. 1997. The use of a simple empirical method for objective quantification of the stretchability of cheese on cooked pizza pies. J. Food Engineering 31:147-161.

Kindstedt, P. S. 1995. Factors affecting the functional characteristics of unmelted and melted Mozzarella cheese. Pages 27-41 in Chemistry of Structure-Function Relationships in Cheese. E. L. Malin and M. H. Tunick, ed. Plenum Press, New York, NY.

Kindstedt, P. S., J. K. Rippe, and C. M. Duthie. 1989a. Application of helical viscometry to study commercial Mozzarella cheese melting properties. J. Dairy Sci. 72:3123-3128.

Kindstedt, P. S., J. K. Rippe, and C. M. Duthie. 1989b. Measurement of Mozzarella cheese melting properties by helical viscometry. J. Dairy Sci. 72:3117-3122.

Marshall, R. T., ed. 1992. Standard Methods for the Examination of Dairy Products. 15th ed. Am. Publ. Health Assoc., Inc., Washington, DC.

McMahon, D. J., R. L. Fife, and C. J. Oberg. 1999. Water partitioning in Mozzarella cheese and its relationship to cheese meltability. J. Dairy Sci. 82:1361-1369.

Oberg, C. J., R. K. Merrill, R. J. Brown, and G. H. Richardson. 1992. Effects of milk-clotting enzymes on physical properties of Mozzarella cheese. J. Dairy Sci. 75:669-675.

Oberg, C. J., R. K. Merrill, L. V. Moyes, R. J. Brown, and G. H. Richardson. 1991. Effects of Lactobacillus helveticus culture on physical properties of Mozzarella cheese. J. Dairy Sci. 74:41014107.

Olson, N. F., and W. V. Price. 1958. A melting test for pasteurized process cheese spread. J. Dairy Sci. 41:999-1000.

Peña, J. L., A. Anzaldúa-Morales, G. Gastélum, and V. Nevárez. 1996. A probe for measuring stretchability (string) of melted cheese by instrumental means. Page 186 in Proc. Inst. Food Technologist Ann. Mtg. New Orleans, LA. (Abstr.)

U. S. Department of Agriculture. 1980. USDA Specifications for Mozzarella cheeses. Agric. Marketing Service, USDA, Washington, DC.

U. S. Environmental Protection Agency. 1992. Inductively coupled plasma-atomic electron spectroscopy. Method 6010a (Revision 1) in Test Methods for Evaluating Solid Waste, Vol. 1A. Laboratory Manual Physical/Chemical Methods. Office of Solid Waste and Emergency Response, U.S. Environmental Protection Agency, Washington, DC. 